\title{
R\&D ALLIANCE PARTNER ATTRIBUTES AND INNOVATION PERFORMANCE: A FUZZY SET QUALITATIVE COMPARATIVE ANALYSIS
}

\begin{tabular}{|r|l|}
\hline Journal: & Journal of Business and Industrial Marketing \\
\hline Manuscript ID & JBIM-07-2020-0314.R1 \\
\hline Manuscript Type: & Original Article \\
\hline Keywords: & Partners, coopetition, fuzzy set analysis, R\&D alliances, KBV \\
\hline \multicolumn{2}{|l}{} \\
\end{tabular}

\section{SCHOLARONE ${ }^{\mathrm{m}}$ \\ Manuscripts}




\title{
R\&D ALLIANCE PARTNER ATTRIBUTES AND INNOVATION PERFORMANCE:
}

\section{A FUZZY SET QUALITATIVE COMPARATIVE ANALYSIS}

\begin{abstract}
Because $R \& D$ alliances are important means for fostering firm innovation performance, research has investigated their key drivers. However, multiple configurations of R\&D alliance drivers may lead to firm innovation performance. Drawing upon the knowledge-based view of alliances, we investigate configurations of $R \& D$ alliance factors leading to high innovation performance in allied firms by focusing on partner attributes (i.e., technological relatedness, competitive overlap, experience, relative size). Then, using a fuzzy set qualitative comparative analysis, we dissect the configurations of these factors in $27 \mathrm{R} \& \mathrm{D}$ alliances formed by 54 telecom firms worldwide. We find that good R\&D alliance partners are technologically related competitors with no experience in forming R\&D alliances.

Alternatively, competitors can achieve high innovation performance when they have experience in doing R\&D alliances and are not technologically related. Drawing on these findings, we submit a set of propositions with relevant implications for the knowledge-based view of alliances and coopetition research.
\end{abstract}

Keywords: knowledge-based view of alliances; R\&D alliances; partner attributes; qualitative comparative analysis; fuzzy-set analysis; telecom industry; coopetition 


\section{Introduction}

R\&D alliances are intensively used by firms operating in high technology industries (George et al., 2001) and serve as an important means for fostering firm innovation performance (Sampson, 2007). For example, R\&D alliances allow firms to access a greater collection of information types (Lahiri and Narayanan, 2013) and leverage such knowledge to confront technological discontinuities (Vasudeva and Anand, 2011). Drawing upon the importance of R\&D alliances in driving firm innovation performance, extant research has largely examined how multiple configurations of partner attributes lead to firm innovation performance (Belderbos et al., 2004; Reuer and Devarakonda, 2017). Therefore, existing research has individually analyzed the impact of R\&D alliance partner attributes on firm innovation performance. Despite such analyses, research has generally underestimated the configurations of partner attributes leading to firm innovation performance. This research gap is interesting to explore since firms involved in R\&D alliances usually face a combination of partner attributes (Lavie, 2007; Mindruta et al. 2016). For instance, in 2010 Sony Corp., a giant Japanese manufacturer of consumer and professional electronics, gaming, and entertainment headquartered in Kōnan (Tokyo), formed an R\&D alliance with its American contender Google Inc. to explore the joint development of new compelling Android-based hardware products for the home, mobile, and personal product categories. The two partners registered the patents in the same 2039 technology classes and had previously formed R\&D alliances with few other partners. Gaining a better understanding of how R\&D partner attributes tie into configurations is an issue that is attracting particular interest in coopetition research (Bouncken et al., 2020) and alliance literature (Lavie, 2007; Mindruta, 2013).

This paper aims to acquire a better knowledge regarding this underrated but nonetheless important aspect of alliances. Specifically, we ask the following question: what configurations of R\&D alliance partner attributes lead firms involved in $R \& D$ alliances to achieve high 
innovation performance? To tackle this question, we first review the extant literature on R\&D alliances and rely on the knowledge-based view (henceforth, KBV) of alliances (Grant and Baden-Fuller, 2004; Vasudeva and Anand, 2011) to identify partner attributes in R\&D alliances. We single out four main partner attributes: (a) partner technological relatedness; (b) partner competitive overlap; (c) partner experience; and (d) partner relative size. Then, we assess the effects of the interrelationships among the attributes by searching beyond the effects of each attribute alone (Bedford and Sandelin, 2015). Our proposed idea is that "the whole is best understood from a systemic perspective and should be viewed as a constellation of interconnected elements" (Fiss et al., 2013). To tackle this idea, we use a fuzzy set qualitative comparative analysis (henceforth fsQCA) (Fiss, 2007; Ragin, 2008) to capture the full range of conjuncture-tied causations among the attributes without requiring any preliminary assumptions about linearity or additivity, and allowing for equifinality (Schneider and Wagemann, 2012).

Specifically, we explore the multiple configurations of partner attributes of $27 \mathrm{R} \& \mathrm{D}$ alliances formed in 2010 leading to innovation performance of 54 telecom firms worldwide. We collected the alliance data by using the Factiva database and the firm innovation performance data by utilizing the QPAT and OECD World Bank databases.

The findings of the fuzzy set analysis allow us to provide contributions to both alliance literature that used the KBV and coopetition research. First, this study shows the relevance of how partner attributes (i.e., partner technological relatedness, partner competitive overlap, partner experience, and partner relative size) tie, with regard to the firms' access to external knowledge (Caner and Tyler, 2015) and consequently to their willingness to achieve high innovation performance (Grant and Baden-Fuller, 2004; Lavie, 2007; Mindruta et al., 2016). Second, this paper contributes to coopetition research because it reveals the beneficial effect of coopetition for the innovation performance of the firms involved in R\&D alliances when 
some of the other knowledge-based partner attributes are considered (Filiou and Massini, 2018; Hani and Dagnino, 2020; Park et al., 2014; Ritala and Hurmelinna-Laukkanen, 2013; Wang et al., 2019).

The paper is structured as follows. Section two reviews the KBV of alliances to identify R\&D alliances partner attributes and to discuss the importance of detecting the multiple configurations leading to firm innovation performance. Section three describes the fsQCA methodology used in the paper. Section four discusses the findings of the study and offers two propositions that support the KBV of R\&D alliances between coopetitors. The final section offers the conclusion, assesses the limitations, and provides a few directions for performing future research.

\section{Theoretical background}

Recent studies in the KBV domain showed that the knowledge base of many industries (especially hi-tech industries) is complex and rapidly changing, and consequently, several firms find it increasingly difficult to cultivate in-house all scientific knowledge required (Sampson, 2007). According to these studies, this knowledge gap can be filled by prioritizing the formation of R\&D alliances. The KBV literature suggests that R\&D alliances allow firms to acquire a broad range of information (Lahiri and Narayanan, 2013) that can be used to tackle technological discontinuities (Vasudeva and Anand, 2011) and benefit from accelerated growth rates (Belderbos et al., 2004). Additionally, R\&D collaborations allow firms to expand their technical knowledge base because each alliance partner has a unique knowledge base and purposely maintains this knowledge base even after forming R\&D alliances (Grant and Baden-Fuller, 2004). Based on this logic, the KBV of alliances suggests that firms form R\&D alliances to gain the right to access external knowledge (Caner and Tyler, 2015; Grant and Baden-Fuller, 2004; Vasudeva and Anand, 2011) which, in turn, allows them to achieve and sustain innovation performance (Grant and Baden-Fuller, 2004). 
Based on this assumption, the R\&D alliance literature indicates that gaining knowledge access might depend on several partner attributes that, because of the knowledge domain that can be accessed through the R\&D alliance (Steensma and Corley, 2000), lead allied firms to achieve high innovation performance (Gnyawali and Park, 2011). We observe that partner diversity, partner size, partner geographical distance, partner technological relatedness, partner competitive overlap, partner experience, and partner proximity affect firm innovation performance (Anand and Khanna, 2000; Diestre and Rajagopalan, 2012; Gnyawali and Park, 2011; Petruzzelli, 2011). However, due to the substantial overlap among the various partner attributes, the proliferation of partner attributes has generated conceptual ambiguity that risks diluting the significance of the knowledge that can be accessed through R\&D alliance partners, while also hindering the impact of empirical research (Capaldo and Petruzzelli, 2014).

In this regard, some considerations might be offered. First, extant research shows that firms' ability to access different types of knowledge depends on whether the firms' partners possess knowledge in similar technological domains (Diestre and Rajagopalan, 2012; Rothaermel and Boeker, 2008) that can be assimilated and utilized (Lane and Lubatkin, 1998).

Second, the literature suggests that the knowledge that can be accessed also depends on whether the R\&D alliance partners generate (Belderbos et al., 2004; George et al., 2001) or recombine knowledge in the same business area (Dussauge et al., 2000; Gnyawali and Park, 2011). Third, numerous studies indicate that the firms' ability to access knowledge relies on the routines and experiences developed by each partner through previous alliances (Anand and Khanna, 2000). Fourth, some studies show that the knowledge that can be accessed by other alliance partners also depends on the larger partners' amount of tangible and intangible resources (Lahiri and Narayanan, 2013). 
Given their grounding in the KBV of alliances, we believe that four factors (i.e., partner technological relatedness, partner competitive overlap, partner experience, and partner relative size) could improve our understanding of how partner attributes in R\&D alliances affect firm innovation performance.

\subsection{Partner technological relatedness}

This partner attribute indicates that firms possessing knowledge in similar technological domains are more likely to form and build better performing R\&D alliances (Frankort, 2016; Lane and Lubatkin, 1998; Rothaermel and Boeker, 2008). According to the KBV of alliances, partner technological relatedness affects the innovation performance of R\&D alliances because the partners involved rely on similar knowledge bases (Diestre and Rajagopalan, 2012; Frankort, 2016). This reasoning is connected to the assumption that partners who possess similar knowledge bases are better able to assimilate and utilize each other's knowhow (Lane and Lubatkin, 1998), thereby increasing the value created through their R\&D collaboration (Frankort, 2016).

\subsection{Partner competitive overlap}

Partner competitive overlap indicates that the partners are coopetitors because they are involved in the R\&D alliance and generate knowledge in the same business area (Belderbos et al., 2004; Bengtsson and Kock, 2000). Moreover, partners can be coopetitors when they are competitors in one product market and supply chain partners in another product market (Bengtsson and Kock, 2000). This is especially true when the R\&D alliance is formed by two large firms (Gnyawali and Park, 2011). In this regard, some studies argue that coopetitors are likely to have complementary resources that allow for the synergistic recombination of knowledge (Dussauge et al., 2000; Gnyawali and Park, 2011). Additionally, coopetitors have 
relatively similar knowledge bases (Filiou and Massini, 2018; Park et al., 2014) and such knowledge similarity enhances the potential absorptive capacity (Lane and Lubatkin, 1998) by facilitating the exchange of partners' codified and tacit knowledge (Ritala and HurmelinnaLaukkanen, 2013). Drawing upon these advantages, scholars found that alliances between two coopetitors stimulate the development of new products and their introduction in the market (e.g., Gnyawali and Park, 2011).

\subsection{Partner experience}

Partner experience includes both the general experience a firm has accumulated by forming any prior alliance and the partner-specific experience that the firm has accrued through repeated alliances with the same partner (Hoang and Rothaermel, 2005). According to the KBV of alliances, previous alliances enable partners to accumulate knowledge about each other's intangible R\&D resources, which, in turn, allows the alliance partners to pursue new knowledge opportunities together (Reuer and Devarakonda, 2017). Moreover, some studies found that partners with more alliance experience had, on average, more knowledge regarding how to leverage innovations from their previous alliances (Duysters et al., 2012), especially when these alliances are successful (Jones et al., 2003). Additionally, other studies showed that alliance partners with more experience develop routines to combine their knowledge with that of previous and current alliance partners (Anand and Khanna, 2000), which, in turn, increases their absorptive capacity (Lane and Lubatkin, 1998) and their innovation performance (Bouncken and Fredrich, 2016).

\subsection{Partner relative size}

Larger partners are often endowed with valuable resources that enhance firm performance (Lahiri and Narayanan, 2013). Larger partners' resources, including tangible and intangible 
assets, such as human resources, financial assets, marketing efforts, R\&D investments, and reputation, can potentially be accessed by the focal firm through the alliance (Lavie, 2007). Moreover, larger partners are more suited for acquiring the broad domain of knowledge encapsulated in the partner firms' organizational capital (Belgraver and Verwaal, 2017) and integrate it inside their organizations (Grant, 1996).

\subsection{Configurations of $R \& D$ alliance partner attributes leading to firm innovation performance}

R\&D alliances typically entail high levels of partner attribute interdependence, especially when two or more firms cooperate in the development of products or processes by combining their complementary know-how (Steensma and Corley, 2000). Thus, combining partner attributes is highly relevant for firm's innovation performance (Boschma, 2005). The combinatory effects of partner attributes and the underlying mechanisms received attention from the literature (Lavie, 2007; Mindruta et al., 2016). For instance, Lavie (2007) found that combining the network resources of distinct partners in an alliance portfolio contributes to firm performance. Moreover, Mindruta et al. (2016) identified the combinations of attributes that are complements or substitutes in alliance formation and assessed their relative importance in driving partner selection. Although these studies provided valuable insights improving our comprehension of the effects of alliance partner attributes, this paper differs and complements the studies reported above in three ways. First, scholars have rarely explored firm innovation outcomes by examining the combinatory effects of alliance partner attributes. Surprisingly, these effects are considered highly relevant to grasp firm innovation performance (Boschma and Ter Wal, 2007), especially in coopetition research (Bouncken et al., 2020). 
Second, scholars have mostly developed arguments rooted in theoretical perspectives focused on firm resources. Conversely, a better understanding of the combinatory effects of R\&D alliance partner attributes requires today the development of arguments informed by theoretical perspectives based on knowledge, such as the KBV of alliances (Grant and BadenFuller, 2004).

Finally, extant research has fallen short to explore the relevance of these effects by using quantitative methods. To unearth the combinatory effects of alliance partner attributes leading to firm innovation performance, research should analyze these issues by exploring beyond the effects of each attribute alone (Bedford and Sandelin, 2015).

Given the reasons above, by studying the combinatory effects of R\&D alliance partner attributes, this paper aims to gain a better understanding of the effect of the four partner attributes reported above on firm innovation performance.

\section{Method: a fuzzy set qualitative comparative analysis}

\subsection{The model}

We employed fsQCA to test the relationship between the four partner attributes of R\&D alliances and firm innovation performance. The fsQCA is useful for investigating the causal relationships existing between a set of conditions and the phenomenon of interest, called outcome (Ragin 2000; Ragin, 2014; Schneider and Wagemann, 2012). It relies on Boolean algebra and conceptualizes cases as combinations of conditions. It aims at verifying whether and which of the conditions are linked to the presence of the outcome, through coded procedures, dedicated algorithms and software (Dusa, 2019). More specifically, the fsQCA allows identifying the existence of necessary and sufficient conditions for the outcome to occur (Fiss, 2011). A condition is defined sufficient when its presence is enough for the outcome to occur, and it is defined necessary when the outcome cannot occur when the 
condition is absent. Necessity and sufficiency can refer both to each condition, considered individually, and to combinations of conditions (conjunctural causation; Ragin and Rihoux, 2009). Also, the fsQCA allows considering asymmetrical associations between the sufficient conditions and the outcome, since it does not assume that the absence of sufficient conditions necessarily generates the absence of the outcome (Schneider and Wagemann, 2012).

We adopted fsQCA for two reasons. First, fsQCA has recently gained prominence in R\&D management research (Iseke et al., 2015) because it presents various advantages in detecting multiple patterns leading to the outcome (equifinality; Fiss, 2007). Accordingly, fsQCA is uniquely suitable for detecting the configuration of attributes as it enables an advanced assessment of how different causes combine to affect relevant outcomes (Fiss, 2007; Ragin, 2008), such as the innovation performance of firms involved in R\&D alliances.

Second, fsQCA overcomes the considerable challenges that both qualitative case-oriented research and quantitative variable-oriented methods face in assessing equifinality. By using fsQCA, we analyzed an extensive number of different combinations of elements (i.e., a major challenge in qualitative case-oriented research), and this understanding allowed us to strip away the elements that are not involved with the outcomes (i.e., a major challenge in quantitative variable-oriented methods). Given the motives above, we believe that fsQCA is a method suitable for examining data and obtaining findings that may allow us to advance our knowledge of R\&D alliance configurations (Marx and Dusa, 2011). To our knowledge, no previous inquiry used this method to explore the combinatory effects emerging in the strategic alliance domain.

\subsection{Case and data selection}

We selected cases of R\&D alliances formed worldwide in the telecom industry in 2010 (Sampson, 2007). We believe this industry is appropriate for conducting this study for two 
reasons. First, previous research showed a high incidence of international R\&D alliances in the telecom industry (Sampson, 2007). Second, we chose this industry because of its importance along the dimensions of interest. Since we used patent data to measure firm innovation performance, we decided to investigate $R \& D$ alliances formed in an industry in which firms regularly patent their inventions (Hagedoorn and Cloodt, 2003).

We decided to examine the year 2010 for two reasons. First, 2010 is a particularly interesting year in the telecom industry. Previous research showed that telecom firms have, on average, registered numerous collaborations in R\&D activities in 2010 (Ferrigno, 2016).

Second, a widely used study on the global telecommunication industry reported that, in 2010, collaborations in R\&D activities were an important means of spreading the development costs of network technologies, such as $4 \mathrm{G}$ wireless broadband (EY, 2015).

The alliance data used in this study were downloaded from the Factiva database, which contains data comprising worldwide business information, including R\&D alliances, starting from 1994 (Lavie, 2007). Additionally, we collected 35 transcripts of interviews with key managers directly involved in the alliance cases.

By relying on the Factiva database, we captured the entire population of R\&D alliances formed worldwide in the telecom industry in 2010. More specifically, we collected data that allowed us to identify all R\&D alliances formed worldwide in the telecom industry in 2010 . In particular, we identified $34 \mathrm{R} \& \mathrm{D}$ alliance cases formed by 77 telecom firms worldwide. We refined the set in two ways. First, we dropped one alliance case due to missing data. Second, we excluded 6 alliance cases (including 5 triadic and 1 multi-partner alliances) to prevent obtaining conflated results due to the inclusion of multiple levels of analysis, thereby restricting our set to dyadic R\&D alliance cases. Ultimately, the final set of cases consisted of 27 dyadic R\&D alliance cases formed by 54 telecom firms worldwide with a broad geographical mix (of the 54 telecom firms, 19 are American, 18 are firms based in Europe, and 
the remaining 17 are firms headquartered in Asia). For this restricted set of alliance cases, Factiva database enabled access to 23 transcripts of interviews with Chairman, Chief Executive Officer, Chief Operating Officer, and Chief Technology Officer of the partners involved in the alliances. Questions about the prospective knowledge created through the alliance, the benefits brought by the partners, and actual and future developments of the partnership were addressed in the interviews when the alliances were formed. The interviews covered $60 \%$ of the alliances under scrutiny.

To measure innovation performance at the global level, we also used the following extensive and updated source of patent information: the QPAT database (Baglieri et al., 2014).

Additionally, by using this database, we were able to perform a citation search, not only on a subject patent but also on every other member of its patent family. This condition allowed us to gather a much broader set of results for our alliance cases. Using the QPAT database, we collected the patents filed by the 54 telecom firms worldwide from 2011 to 2013.

\subsection{Partner attributes measures}

\subsubsection{Partner technological relatedness}

According to prior literature (Diestre and Rajagopalan, 2012), we measured partner technological relatedness by examining the extent to which the firms involved in the R\&D alliance cases registered patents in the same technology classes. To measure this partner attribute, we first collected and identified all patents granted to each partner per alliance case during the period 2007-2009. The selection of this three-year window lessened fluctuations and provided the opportunity to collect updated knowledge stocks of the firms involved in each alliance case (Rothaermel and Boeker, 2008). Then, we counted the number of patent classes (from 2007 to 2009) that were shared among the partners. Thus, consistent with our reasoning of partner technological relatedness, a larger number of common patent classes 
among partners indicates a greater amount of knowledge that can be assimilated by each partner involved in the alliance.

\subsubsection{Partner competitive overlap}

Regarding partner competitive overlap, we coded the 27 alliances according to the following two labels: (a) horizontal alliance, when the alliance is established by firms at the same level of the value chain (horizontal) and (b) vertical alliance, when the alliance is established by firms at a different level of the value chain. While we are aware that prior studies recognized the existence of other alliance structures (George et al., 2001), we codified partner competitive overlap as a crisp-set condition ( 1 for a horizontal alliance vs. 0 for a vertical alliance) to minimize problems related to interpretation that might occur due to the coding of partner competitive overlap.

\subsubsection{Partner experience}

To compute partner experience, we calculated partner experience by measuring the number of alliances the alliance partners had formed before the focal alliance (Hoang and Rothaermel, 2005). Specifically, we considered the average number of alliances the partners had formed before the alliance event. The content of the Factiva alliance database allowed us to obtain data collected from 1994 to compute this variable.

\subsubsection{Partner relative size}

Previous alliance studies used the total number of employees of the partners involved in an alliance as a proxy of firm size (Lahiri and Narayanan, 2013). We acknowledge that differences in partner size may indicate an alliance dynamic different from that of alliances between equal partners (Gulati and Singh, 1998). Thus, to improve consistency we 
operationalized partner relative size as the ratio of the total number of employees of the two alliance partners $_{i}$ and ${ }_{j}$ as follows: where Total number of employees ${ }_{i}>$ Total number of employees $\mathrm{j}_{\mathrm{j}}$

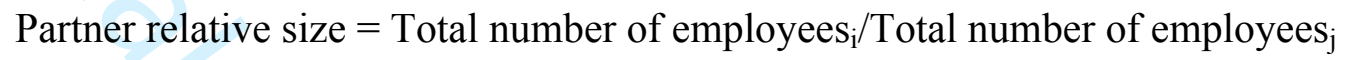

\subsection{Innovation measure}

To measure innovation performance, we selected the number of patents as a proxy for measuring innovation performance for two reasons. First, the number of patents filed provides a consistent measure of new knowledge generation (Hagedoorn and Cloodt, 2003).

Second, due to the wide availability of patent data in many technology industries (Sampson, 2007), including the worldwide telecom industry, patents represent an accessible and reliable proxy for innovation performance. In this study, we computed the number of patents filed before and after the alliance formation. Since the patent publication process may take years, previous studies counted only the number of patents filed by the alliance partners after the formation of the alliances (see Deeds and Hill, 1996). After a thorough reflection, we believe that this kind of operationalization may bias the results. Thus, to ensure more consistency we decided to measure innovation performance as the ratio between the number of patents filed immediately after the alliance (from 2011 to 2013) and the number of patents filed before the formation of the alliance (from 2007 to 2009). Table I reports descriptive statistics of the firms involved in the $27 \mathrm{R} \& \mathrm{D}$ alliance cases.

\section{[Insert Table I about here]}

\subsection{Calibration}

Previous QCA studies indicated that the initial step in performing a thorough fuzzy set analysis is to calibrate the dataset to obtain the calibrated membership scores of the cases 
(Ragin, 2008). The calibrated scores derive from three qualitative anchors which are calculated for each condition and the outcome and correspond respectively to the full nonmembership, the crossover point and the full membership (Ragin, 2008).

Regarding the conditions, the anchors were identified by analysing the internal distribution of the cases and searching for discontinuities that result in clusters, in coherence with the extant literature on the topic (Dusa, 2019; Jenson et al., 2016).

Regarding the innovation performance measure, we decided to perform a theory-driven calibration to derive the three qualitative anchors (Fiss et al., 2013). Mittal et al. (2013) found that differences in patent activity occur among countries. Consistent with this finding, we externally calculated the anchors for the innovation performance measure by considering the number of patents granted in the countries of residence of all alliance partners included in our database. Primarily, we collected these data from the OECD World Bank database, which considers firms operating in the following technology domains and IPC referring to the telecom industry: H01P, H01Q, H01S, H03B, H03C, H03D, H03H, H03 M, H04B, H04J, H04K, H04 L, H04 M, H04Q, G01S, G08C, and G09C. Then, for each country, we calculated an index by dividing the number of patents granted in the country between 2011 and 2013 by the number of patents granted in the same country between 2007 and 2009. The computation of the index is consistent with our measurement of innovation performance. Finally, we evaluated the qualitative anchor for full membership by considering the highest value among the indexes and the qualitative anchor for full non-membership by considering the lowest value among the indexes. Also, we assessed the qualitative anchor for the crossover point by considering the median value of the indexes (Goncalves et al., 2016). Table II lists calibration rules and membership scores, and results are presented in the following section.

\section{[Insert Table II about here]}

\section{Results and discussion}


The calibrated dataset was tested for necessity and no condition passed the consistency threshold of 0.90 for a necessary condition (Legewie, 2013).

The truth table in Table III shows per each row the configurations of conditions that we draw from our sample, and the corresponding number of cases per configuration. The asterisk marks the combinations associated with the presence of the outcome (see Schneider and Wagemann, 2012, for more details).

\section{[Insert Table III about here]}

Table IV presents the results of the fuzzy set analysis for sufficiency by using the typical notation, as suggested by Ragin and Fiss (2008). Our sufficiency test used a consistency threshold of 0.85 and a frequency threshold of 1 (Ragin, 2008). As shown in Table IV, we found that two alternative configurations of partner attributes lead the allied partners to achieve high innovation performance in $\mathrm{R} \& \mathrm{D}$ alliances: 1) a configuration with extensive partner technological relatedness and competition but no experience (consistency: 0.946; raw coverage: 0.194); and 2) a configuration with extensive partner experience and competition but no technological relatedness (consistency: 0.949; raw coverage: 0.197). The abovedetailed results were assessed for robustness (Skaaning, 2011) by performing the fsQCA with different calibration thresholds and consistency thresholds (alternative consistency thresholds: 0.83 and 0.87 ) and robustness check confirmed the results.

\section{[Insert Table IV about here]}

In configuration 1 , good R\&D alliance partners are competitors that generate knowledge in similar technology domains and are not experienced in doing R\&D alliances. An example of this configuration in our data is the R\&D alliance between Sony Corp and Google Inc. Sony Corp. motivated the R\&D partnership in the following terms:

"The combination of Sony as industry-leading product design, engineering, and development expertise with the flexibility and growth potential of Google as innovative, open-source 
Android platform will provide consumers with a world of new and exciting Internet user experiences" (Sony CEO, Press Release, 2010).

Configuration 2 shares the same basic factors with configuration 1, but with a nontrivial difference; i.e., partner experience and partner technological relatedness are inverted. Rather than being inexperienced and technologically related, in this configuration "good" R\&D alliance partners are competitors that generate knowledge in dissimilar technological domains and have prior experience in forming alliances.

In our sample, an instance of this configuration may be found in the joint venture formed by Deutsche Telekom and Orange France Telecom. France Telecom explained the formation of the alliance in the following terms:

"By drawing on the resources of Deutsche Telekom and Orange France Telecom, and on experienced management and staff in the United Kingdom, we are confident that we will leverage on identified synergies and generate significant value for our shareholders" (Orange France Telecom CEO, Press Release, 2010).

These two configurations characterize the key theoretical contribution of this study to coopetition and alliance research as they provide an encompassing picture of the factors that do, and do not, lead to high innovation outcomes (Belderbos et al., 2004; Reuer and Devarakonda, 2017) when alliance partners are coopetitors (Bengtsson and Kock, 2000).

\section{1. “Good” R\&D alliance coopetitors: technologically related and inexperienced partners} According to the KBV of alliances, coopetitors are likely to have complementary resources that allow for the synergistic recombination of knowledge (Dussauge et al., 2000; Gnyawali and Park, 2011). Additionally, coopetitors have relatively similar knowledge bases (Park et $a l ., 2014$ ) and such knowledge similarity enhances potential absorptive capacity (Lane and Lubatkin, 1998) by facilitating the exchange of partners' codified and tacit knowledge (Ritala 
and Hurmelinna-Laukkanen, 2013). Drawing upon these advantages, scholars found that alliances between two coopetitors stimulate the development of new products and their introduction into the market (e.g., Gnyawali and Park, 2011). Our study enriches the understanding of this phenomenon and thus contributes to the literature on partner competitive overlap by showing that a high level of partner technological relatedness and a low level of partner experience play a contingent role on the impact of partner competitive overlap on firm innovation performance.

On one hand, we observe that partners with similar technological strengths are more likely to share knowledge in the R\&D alliance because of their similar knowledge bases (Lane and Lubatkin, 1998). Since partners possess similar knowledge bases, their ability to assimilate and use each other's know-how increases (Diestre and Rajagopalan, 2012). Thus, this study contributes to the literature on partner competitive overlap by showing that the impact of partner competitive overlap on firm innovation performance is amplified when competitors possess similar technological strengths that augment their willingness to share knowledge in the R\&D alliance.

On the other hand, we note that partners without experience in forming alliances enable the allied firms to unlock more knowledge in the R\&D alliance. This enabling effect occurs as alliance partners have not yet developed the appropriate routines to combine their knowledge with previous and current alliance partners (Anand and Khanna, 2000). As a result, this study contributes to the literature on partner competitive overlap by showing that the impact of partner competitive overlap on firm innovation performance is also amplified when competitors without alliance experience have not developed knowledge about how to leverage innovations from their previous alliances (Duysters et al., 2012).

Taken together, the two theoretical arguments discussed above allow us to offer insights into the relationship between partner competitive overlap and firm innovation performance. More 
specifically, we show that competitors, if allied with technologically related partners and inexperienced partners, can augment their willingness to share their knowledge in the R\&D alliance. Thus, we propose the following proposition:

Proposition 1). The combination of technologically related and inexperienced partners is a sufficient condition to generate high innovation performance when the alliance partners are coopetitors.

\section{2. “Good" $R \& D$ alliance coopetitors: technologically unrelated and experienced partners}

According to the KBV of alliances, when firms are engaged in horizontal alliances, they have access to the resources and knowledge that their partners-competitors share in R\&D alliances (Dussauge et al., 2000). This condition, in turn, allows the firms to create new knowledge stemming from collaboration with their partners-competitors. Our study enhances the comprehension of this phenomenon and thus contributes to the literature on partner competitive overlap by showing that a low level of partner technological relatedness and a high level of partner experience play a contingent role on the impact of partner competitive overlap on firm innovation performance.

On one hand, we found that, when firms are not technologically related, the partners have difficulties in assimilating and utilizing each other's know-how; i.e., their absorptive capacity is severely reduced (Lane and Lubatkin, 1998). Similarly, Lane and Lubatkin (1998) found that firms with lower technological relatedness in basic technologies have lower relative absorptive capacity and, hence, are less likely to learn from each other. Moreover, an extensive technological distance between allied partners entails problems related to communication and mutual understanding (Petruzzelli, 2011). However, some studies propose that the absorptive capacity of partners that are not technologically related can increase when the partners are experienced in forming $R \& D$ alliances, because of their greater mutual 
understanding (Belderbos et al., 2004) and their ability to develop useful routines (Anand and Khanna, 2000; Duysters et al., 2012), which, in turn, increases their absorptive capacity (Lane and Lubatkin, 1998) and their innovation performance (Bouncken and Fredrich, 2016).

On the other hand, we observe that firms developing and establishing routines and procedures to generate and integrate knowledge from earlier alliance experiences inevitably become entrapped in this capability. In fact, by continuously focusing on similar alliance experiences, firms increasingly tend to invest less effort in exploring new alliance activities and limit their opportunity to develop tacit knowledge in R\&D alliances with other potential partners (Deeds and Hill, 1996). In turn, this condition affects subsequent alliance activity and, over time, the knowledge gathered from previous alliances depreciates. Knowledge traps may be circumvented by becoming involved in R\&D alliance partners that are not technologically related. In particular, alliance partners that are not technologically related introduce knowledge stemming from different technological domains (Diestre and Rajagopalan, 2012). Thus, the diversity of the knowledge that can be leveraged in the alliance may generate synergies and economies of cognitive scope that overcome the knowledge traps that might emerge from the partners' experience in following alliance activities (Filiou and Massini, 2018). This result is consistent with previous works that used industrial network theory in strategic alliances (Gulati et al., 2000).

The two theoretical arguments discussed above allow us to understand better the relationship between partner competitive overlap and firm innovation performance. More specifically, in this study we show that competitors, if allied with partner technologically unrelated and experienced partners, can augment their access to the resources and knowledge that they share in R\&D alliances (Dussauge et al., 2000). Therefore, we suggest the following proposition: 
Proposition 2). The combination of technologically unrelated and experienced partners is a sufficient condition to generate high innovation performance when the alliance partners are coopetitors.

\section{Conclusion}

Despite its relevance to firm innovation performance, understanding the configurations of R\&D alliance partner attributes leading the allied firms to achieve high innovation performance is an issue that the extant alliance literature has largely overlooked (Boschma and Ter Wal, 2007). In this study, we first embraced the KBV of alliances (Grant and BadenFuller, 2004; Vasudeva and Anand, 2011) to extract the individual factors that affect innovation performance in firms involved in R\&D alliances. More precisely, we identified the following four partner attributes: (1) partner technological relatedness; (2) partner competitive overlap; (3) partner experience; and (4) partner relative size. Then, to detect the combinatory effects of the four partner attributes, we conducted a thorough qualitative comparative case study of 27 R\&D alliances formed in the telecom industry worldwide in 2010 . The findings of the fuzzy set analysis unmistakably show that a very high level of partner competitive overlap is beneficial for firm innovation performance when other knowledge-based partner attributes (such as partner technological relatedness and partner experience) are considered.

\subsection{Implications for theory development}

This study offers four theoretical contributions. First, we contribute to the KBV of alliances (Grant and Baden-Fuller, 2004; Vasudeva and Anand, 2011) by highlighting the importance of the configurations of partner attributes for firm innovation performance (Lavie, 2007; Mindruta et al., 2016). Our results suggest that the combinations between the four key partner attributes leading to firm innovation performance (i.e., partner technological relatedness, 
partner competitive overlap, partner experience, and partner relative size) allow the allied firms to gain the right to access external knowledge (Caner and Tyler, 2015), which, in turn, consents them to achieve and sustain innovation performance (Grant and Baden-Fuller, 2004). Second, we submit a contribution to the coopetition literature (Hani and Dagnino, 2020; Ritala and Hurmelinna-Laukkanen, 2013; Wang et al., 2019). Previous research suggested that partner competitive overlap does not lead allied firms to achieve high innovation performance. Filiou and Massini (2018) found that firms may not be able to exploit the full potential of the research synergies that can arise from alliances with partners within the same industry and partner competitive overlap does not positively impact firm's patents. Other scholars indicated that a moderate level of competition with alliance partners is more beneficial than a very high or a very low level of competition (e.g., Crick, 2019; Park et al., 2014).

Instead, this paper suggests that a very high level of partner competitive overlap is beneficial for firm innovation performance when other knowledge-based partner attributes are considered. Moreover, previous coopetition research has shown that competitors can have no technological relatedness (Chen, 2008). In our study, the first configuration shows partner technological relatedness but no experience while, in the second configuration, the absence of technological relatedness is combined with experience. This finding seems to be contradictory with the literature on coopetition that argues that cooperating with a direct competitor is risky because of the risks of knowledge leakages and spillovers (Estrada et al., 2016). These high risks of opportunism inevitably create tensions (Raza-Ullah et al., 2014) that require to be managed for firms to be successful and achieve innovation performance.

Third, we contribute to the KBV of alliances by prioritizing the (combinatory) effects occurring among the four key factors. By examining the combinatory effects among the individual factors leading to firm innovation performance, we enrich our understanding of the 
influence of these factors on the innovation performance of firms involved in an alliance. Specifically, by conducting a fuzzy set analysis, we learned that some factors are more important than others.

Finally, we offer a methodological contribution. By drawing on the results above, we can argue that fuzzy set analysis is well-positioned to help detect the combinatory effects of partner attributes in $\mathrm{R} \& \mathrm{D}$ alliances contexts. Consistently with previous studies (Bouncken et al., 2020; Iseke et al., 2015), we confirm the suitability of fsQCA for management research particularly dealing with R\&D alliances.

\subsection{Managerial implications}

This study also bears two interesting implications for alliance managers. First, the paper suggests that $R \& D$ alliance managers need to be aware that potential alliance partners have multiple attributes leading to firm innovation performance. In this regard, partner competitive overlap is particularly important for gaining a better understanding of firm innovation performance. When looking for strategic partners, managers should try to ally with highly competitive enterprises so as to access their more innovative knowledge. Second, the results also highlight that this beneficial effect of coopetition in R\&D alliances can be amplified in two ways. On the one hand, when the partners involved in the alliance have not yet developed experience in forming alliances. Partners without previous experience supply ideal stimuli to unlock more knowledge in the alliance because new approaches to access and develop knowledge in the alliance could be explored. On the other hand, we detect the situation when the allied partners are developing technologies and products in different areas. When partnering with firms coming from different technological areas, the knowledge diversity that can be leveraged in the alliances could drive alliance managers to generate synergies and economies of scope within the coopetitive alliance. 


\subsection{Limitations and future research}

While this study contributes to our understanding of the configurations of R\&D alliance partner attributes, some limitations should be noted. First, we are aware that alliance scholars stressed the importance of some partner attributes other than those we have considered (Petruzzelli, 2011). Moreover, we are also aware that some of the partner attributes considered could be further disentangled into sub-partner attributes.

Second, the findings of this study are based on the assumption that high innovation performance is fully explained by the number of patents that alliance partners introduce into the market. Other indicators other than patents may well influence high innovation performance (Deeds and Hill, 1996).

Third, we applied fsQCA to explore the combinatory effects of partner attributes in the specific context of R\&D alliances in the telecom industry worldwide, and in a specific time window. Future studies may investigate the configurations of partner attributes in other timing and business areas, including manufacturing, distribution, or marketing alliances, where perhaps other combinatory effects might emerge.

Fourth, we investigated the configurations of $R \& D$ alliance partner attributes by considering alliances cases. We acknowledge that firms increasingly tend to form, not only single alliances, but also collections of alliances usually termed as alliance portfolios. Thus, our line of inquiry could be positively complemented by taking an alliance portfolio perspective (Vasudeva and Anand, 2011) in which other factors leading to firm innovation performance might emerge from the combination of alliances in which a firm is involved.

\section{Competing interest statement}

This research did not receive any specific grant from funding agencies in the public, commercial, or not-for-profit sectors.

\section{References}


Anand, B. N., and Khanna, T. (2000), Do firms learn to create value? The case of alliances. Strategic Management Journal, Vol. 21 No.3, pp. 295-315.

Baglieri, D., Cesaroni, F., and Orsi, L. (2014), Does the nano-patent 'Gold rush' lead to entrepreneurial-driven growth? Some policy lessons from China and Japan. Technovation, Vol. 34 No.12, pp. 746-761.

Bedford, D. S., and Sandelin, M. (2015), Investigating management control configurations using qualitative comparative analysis: an overview and guidelines for application. Journal of Management Control, Vol. 26 No.1, pp. 5-26.

Belderbos, R., Carree, M., and Lokshin, B. (2004), Cooperative R\&D and firm performance. Research Policy, Vol. 33 No.10, pp. 1477-1492.

Belgraver, H., and Verwaal, E. (2017), Organizational capital, production factor resources, and relative firm size in strategic equity alliances. Small Business Economics, Vol. 50 No.4, pp. 1-25.

Bengtsson, M., and Kock, S. (2000). "Coopetition" in business Networks - to cooperate and compete simultaneously. Industrial Marketing Management, Vol. 39 No. 5, pp. 411-426. Boschma, R. (2005), Proximity and innovation: a critical assessment. Regional studies, Vol. 39, No.1, pp. 61-74.

Boschma, R. and Ter Wal, A.L.J. (2007), Knowledge Networks and Innovative Performance in an Industrial District: The Case of a Footwear District in the South of Italy. Industry and Innovation, Vol. 14, pp. 177-199.

Bouncken, R. B., and Fredrich, V. (2016), Business model innovation in alliances: Successful configurations. Journal of Business Research, Vol. 69 No.9, pp. 3584-3590.

Bouncken, R. B., Fredrich, V., and Kraus, S. (2020), Configurations of firm-level value capture in coopetition. Long Range Planning, Vol. 53 No 1, 101869. 
Caner, T., and Tyler, B.B. (2015), The effects of knowledge depth and scope on the relationship between R\&D alliances and new product development. Journal of Product Innovation Management, Vol. 32 No.5, pp. 808-824.

Capaldo, A., and Petruzzelli, A. M. (2014), Partner geographic and organizational proximity and the innovative performance of knowledge-creating alliances. European Management Review, Vol. 11 No 5, pp. 63-84.

Chen, M. J. (2008), Reconceptualizing the competition-cooperation relationship: A transparadox perspective. Journal of Management Inquiry, Vol. 17 No 4, pp. 288-304. Crick, J.M. (2019), Moderators affecting the relationship between coopetition and company performance, Journal of Business and Industrial Marketing, Vol. 34 No. 2, pp. 518-531. Deeds, D. L., and Hill, C. W. (1996), Strategic alliances and the rate of new product development: an empirical study of entrepreneurial biotechnology firms. Journal of Business Venturing, Vol. 11 No.1, pp. 41-55.

Diestre, L., and Rajagopalan, N. (2012), Are all 'sharks' dangerous? New biotechnology ventures and partner selection in R\&D alliances. Strategic Management Journal, Vol. 33 No.10, pp. 1115-1134.

Dusa, A. (2019), The QCA package, $Q C A$ with $R$. A comprehensive resource. Cham: Springer.

Dussauge, P., Garrette, B., and Mitchell, W. (2000), Learning from competing partners: Outcomes and durations of scale and link alliances in Europe, North America and Asia. Strategic Management Journal, Vol. 21 No.2, pp. 99-126.

Duysters G., Heimeriks K. H., and Lokshin, B., (2012), Do firms learn to manage alliance portfolio diversity? The diversity-performance relationship and the moderating effects of experience and capability. European Management Review, Vol. 9 No.3, pp. 139-152. 
Estrada, I., Faems, D., and de Faria, P. (2016), Coopetition and product innovation performance: The role of internal knowledge sharing mechanisms and formal knowledge protection mechanisms. Industrial Marketing Management, Vol. 53, pp. 56-65.

EY. (2015), Global telecommunications study: navigating the road to 2020.

Ferrigno, G. (2016), Looking for alliance portfolio characteristics: the case of telecom industry. In Das, T. K. (Ed.), Managing Alliance Portfolios and Networks. Charlotte, NC: Information Age Publishing.

Filiou, D., and Massini, S. (2018), Industry cognitive distance in alliances and firm innovation performance. R\&D Management, Vol. 48 No.4, pp. 422-437.

Fiss, P. C. (2007), A set-theoretic approach to organizational configurations. Academy of Management Review, Vol. 32 No.4, pp. 1180-1198.

Fiss, P. C. (2011), Building better causal theories: A fuzzy set approach to typologies in organization research. Academy of Management Journal, Vol. 54 No. 2, pp. 393-420.

Fiss, P. C., Marx, A., and Cambré, B. (2013), Configurational theory and methods in organizational research: Introduction. In: Lounsbury M. (Ed.), Research in the Sociology of Organization (pp. 1-22). Bingley, UK: Emerald Publishing.

Frankort, H. T. (2016), When does knowledge acquisition in R\&D alliances increase new product development? The moderating roles of technological relatedness and product-market competition. Research Policy, Vol. 45 No.1, pp. 291-302.

George, G., Zahra, S. A., Wheatley, K. K., and Khan, R. (2001), The effects of alliance portfolio characteristics and absorptive capacity on performance: A study of biotechnology firms. Journal of High Technology Management Research, Vol. 12 No.2, pp. 205-226. Gnyawali, D. R., and Park, B. J. R. (2011), Co-opetition between giants: Collaboration with competitors for technological innovation. Research Policy, Vol. 40 No.5, pp. 650-663. 
Gonçalves, H. M., Lourenço, T. F., and Silva, G. M. (2016), Green buying behavior and the theory of consumption values: A fuzzy-set approach. Journal of Business Research, Vol. 69 No.4, pp. 1484-1491.

Grant, R. M. (1996), Toward a knowledge-based theory of the firm. Strategic Management Journal, Vol. 17 No.2, pp. 109-122.

Grant, R. M., and Baden-Fuller, C. (2004), A knowledge accessing theory of strategic alliances. Journal of Management Studies, Vol. 41 No.1, pp. 61-84.

Gulati, R., Nohria, N., and Zaheer, A. (2000), Strategic networks. Strategic Management Journal, Vol. 21 No 3, pp. 203-215.

Gulati, R., and Singh, H. (1998), The architecture of cooperation: Managing coordination costs and appropriation concerns in strategic alliances. Administrative Science Quarterly, pp. 781-814.

Hagedoorn, J., and Cloodt, M. (2003), Measuring innovative performance: is there an advantage in using multiple indicators? Research Policy, Vol. 32, pp. 1365-1379. Hani, M. and Dagnino, G.B. (2020), Global network coopetition, firm innovation and value creation. Journal of Business \& Industrial Marketing.

Hoang, H., and Rothaermel, F. T. (2005), The effect of general and partner-specific alliance experience on joint R\&D project performance. Academy of Management Journal, Vol. 48 No.2, pp. 332-345.

Iseke, A., Kocks, B., Schneider, M. R., and Schulze-Bentrop, C. (2015), Cross-cutting organizational and demographic divides and the performance of research and development teams: two wrongs can make a right. $R \& D$ Management, Vol. 45No.1, pp. 23-40. Jenson, I., Leith, P., Doyle, R., West, J., and Miles, M. P. (2016), Testing innovation systems theory using qualitative comparative analysis. Journal of Business Research, Vol. 69No.4, pp. 1283-1287. 
Jones, E., Chonko, L. B., and Roberts, J. A. (2003), Creating a partnership-oriented, knowledge creation culture in strategic sales alliances: a conceptual framework. Journal of Business \& Industrial Marketing.Vol. 18 No. 4/5, pp. 336-352.

Lahiri, N., and Narayanan, S. (2013), Vertical integration, innovation, and alliance portfolio size: Implications for firm performance. Strategic Management Journal, Vol. 34 No.9, pp. 1042-1064.

Lane, P. J., and Lubatkin, M. (1998), Relative absorptive capacity and interorganizational learning. Strategic Management Journal, Vol. 19 No.5, pp. 461-477.

Lavie, D. (2007), Alliance portfolios and firm performance: A study of value creation and appropriation in the US software industry. Strategic Management Journal, Vol. 28 No.12, pp. 1187-1212.

Legewie, N. (2013), An introduction to applied data analysis with qualitative comparative analysis. Forum Qualitative Sozialforschung/Forum: Qualitative Social Research, Vol. 14(3). Retrieved from http://nbn-resolving.de/urn:nbn:de:0114-fqs1303154.

Marx, A., and Dusa, A. (2011), Crisp-set qualitative comparative analysis (csQCA), contradictions and consistency benchmarks for model specification. Methodological Innovations Online, Vol. 6 No.2, pp. 103-148.

Mindruta, D., Moeen, M., and Agarwal, R. (2016), A two-sided matching approach for partner selection and assessing complementarities in partners' attributes in inter-firm alliances. Strategic Management Journal, Vol. 37 No.1, pp. 206-231.

Mittal, S. K., Momaya, K. S., and Agrawal, S. (2013), Longitudinal and comparative perspectives on the competitiveness of countries: learning from technology and the telecom sector. JCC: Business and Economics Research Journal, Vol. 6 No.2, pp. 235-256. 
Park, B. J. R., Srivastava, M. K., andGnyawali, D. R. (2014), Walking the tight rope of coopetition: impact of competition and cooperation intensities and balance on firm innovation performance. Industrial Marketing Management, Vol. 43 No.2, pp. 210-221.

Petruzzelli, A. M. (2011), The impact of technological relatedness, prior ties, and geographical distance on university-industry collaborations: A joint-patent analysis. Technovation, Vol. 31No.7, pp. 309-319.

Ragin, C. C. (2000), Fuzzy-set social science. Chicago: University of Chicago Press. Ragin, C. C. (2008), Redesigning Social Inquiry: Fuzzy Sets and Beyond. Chicago, IL: University of Chicago Press.

Ragin, C. C. (2014), The Comparative Method: Moving beyond Qualitative and Quantitative Strategies. Oakland: Univ of California Press.

Ragin, C. C., and Fiss, P. C. (2008), Net effects analysis versus configurational analysis: an empirical demonstration. In Ragin CC (Ed.) Redesigning social inquiry: Fuzzy sets and beyond (pp. 190-212). Chicago: University of Chicago Press.

Ragin, C. C., and Rihoux, B. (2009), Configurational comparative methods: Qualitative comparative analysis (QCA) and related techniques. Thousand Oaks: Sage.

Raza-Ullah, T., Bengtsson, M., and Kock, S. (2014), The coopetition paradox and tension in coopetition at multiple levels. Industrial Marketing Management, Vol. 43 No 2, pp. 189-198. Reuer, J. J., and Devarakonda, R. (2017), Partner selection in R\&D collaborations: effects of affiliations with venture capitalists. Organization Science, Vol. 28 No.3, pp. 574-595. Ritala, P., and Hurmelinna-Laukkanen, P. (2013), Incremental and radical innovation in coopetition: The role of absorptive capacity and appropriability. Journal of Product Innovation Management, Vol. 30 No.1, pp. 154-169. 
Rothaermel, F. T., and Boeker, W. (2008), Old technology meets new technology: complementarities, similarities, and alliance formation. Strategic Management Journal, Vol. 29 No.1, pp. 47-77.

Sampson, R. C. (2007), R\&D alliances and firm performance: The impact of technological diversity and alliance organization on innovation. Academy of Management Journal, Vol. 50 No.2, pp. 364-386.

Schneider, C. Q., and Wagemann, C. (2012), Set-theoretic methods for the social sciences: a guide to qualitative comparative analysis. Cambridge, UK: Cambridge University Press. Skaaning, S. E. (2011), Assessing the robustness of crisp-set and fuzzy-set QCA results. Sociological Methods \& Research, Vol. 40 No. 2, pp. 391-408.

Steensma, H. K., and Corley, K. G. (2000), On the performance of technology-sourcing partnerships: the interaction between partner interdependence and technology attributes. Academy of Management Journal, Vol. 43 No. 6, pp. 1045-1067.

Vasudeva, G., and Anand, J. (2011), Unpacking absorptive capacity: a study of knowledge utilization from alliance portfolios. Academy of Management Journal, Vol. 54 No.3, pp. 611-623.

Wang, X., Dolfsma, W., and van der Bij, H. (2019), Individual performance in a coopetitive R\&D alliance: motivation, opportunity and ability. $R \& D$ Management. 
Table I Descriptive statistics of our sample

\begin{tabular}{|c|c|c|}
\hline $\begin{array}{l}\text { Headquarters } \\
\text { location }\end{array}$ & $\begin{array}{l}\text { Number } \\
\text { of firms }\end{array}$ & Percentage \\
\hline Canada & 2 & $3,70 \%$ \\
\hline China & 3 & $5,56 \%$ \\
\hline Finland & 3 & $5,56 \%$ \\
\hline France & 6 & $11,11 \%$ \\
\hline Germany & 1 & $1,85 \%$ \\
\hline India & 4 & $7,41 \%$ \\
\hline Japan & 4 & $7,41 \%$ \\
\hline South Korea & 4 & $7,41 \%$ \\
\hline Sweden & 4 & $7,41 \%$ \\
\hline Taiwan & 4 & $7,41 \%$ \\
\hline Uk & 2 & $3,70 \%$ \\
\hline USA & 17 & $31,48 \%$ \\
\hline Total & 54 & $100,00 \%$ \\
\hline FoundationYear & $\begin{array}{l}\text { Number } \\
\text { of firms }\end{array}$ & Percentage \\
\hline Less than 5 years & 10 & $18,52 \%$ \\
\hline Less than 10 years & 10 & $18,52 \%$ \\
\hline Less than 20 years & 9 & $16,67 \%$ \\
\hline Less than 50 years & 13 & $24,07 \%$ \\
\hline Less than 100 years & 5 & $9,26 \%$ \\
\hline Less than 200 years & 7 & $12,96 \%$ \\
\hline Total & 54 & $100,00 \%$ \\
\hline $\begin{array}{l}\text { Number of patents } \\
(2007-2009)\end{array}$ & $\begin{array}{l}\text { Number } \\
\text { of firms }\end{array}$ & Percentage \\
\hline Less or equal to 500 & 25 & $46,30 \%$ \\
\hline $\begin{array}{l}\text { Less or equal to } \\
1000\end{array}$ & 7 & $12,96 \%$ \\
\hline $\begin{array}{l}\text { Less or equal to } \\
5000\end{array}$ & 10 & $18,52 \%$ \\
\hline More than 5000 & 12 & $22,22 \%$ \\
\hline Total & 54 & $100,00 \%$ \\
\hline
\end{tabular}

\begin{tabular}{|c|c|c|}
\hline $\begin{array}{l}\text { Partner } \\
\text { technological } \\
\text { relatedness }\end{array}$ & $\begin{array}{l}\text { Number } \\
\text { of firms }\end{array}$ & Percentage \\
\hline 0 & 12 & $22,22 \%$ \\
\hline less or equal to 1000 & 30 & $55,56 \%$ \\
\hline less or equal to 2000 & 8 & $14,81 \%$ \\
\hline More than 5000 & 4 & $7,41 \%$ \\
\hline Total & 54 & $100,00 \%$ \\
\hline $\begin{array}{l}\text { Partner } \\
\text { competitors }\end{array}$ & $\begin{array}{l}\text { Number } \\
\text { of firms }\end{array}$ & Percentage \\
\hline Yes & 26 & $48,15 \%$ \\
\hline No & 28 & $51,85 \%$ \\
\hline Total & 54 & $100,00 \%$ \\
\hline $\begin{array}{l}\text { Previous alliances } \\
\text { before } 2010\end{array}$ & $\begin{array}{l}\text { Number } \\
\text { of firms }\end{array}$ & Percentage \\
\hline 0 & 22 & $40,74 \%$ \\
\hline 1 & 8 & $14,81 \%$ \\
\hline Less or equal to 5 & 7 & $12,96 \%$ \\
\hline Less or equal to 10 & 7 & $12,96 \%$ \\
\hline More than 10 & 10 & $18,52 \%$ \\
\hline Total & 54 & $100,00 \%$ \\
\hline Employees in 2010 & $\begin{array}{l}\text { Number } \\
\text { of firms }\end{array}$ & Percentage \\
\hline Less or equal to 10 & 2 & $3,70 \%$ \\
\hline Less or equal to 50 & 3 & $5,56 \%$ \\
\hline Less or equal to 250 & 6 & $11,11 \%$ \\
\hline More than 250 & 43 & $79,63 \%$ \\
\hline Total & 54 & $100,00 \%$ \\
\hline $\begin{array}{l}\text { Number of patents } \\
(2011-2013)\end{array}$ & $\begin{array}{l}\text { Number } \\
\text { of firms }\end{array}$ & Percentage \\
\hline Less or equal to 500 & 26 & $48,15 \%$ \\
\hline $\begin{array}{l}\text { Less or equal to } \\
1000\end{array}$ & 7 & $12,96 \%$ \\
\hline $\begin{array}{l}\text { Less or equal to } \\
5000\end{array}$ & 8 & $14,81 \%$ \\
\hline More than 5000 & 13 & $24,07 \%$ \\
\hline Total & 54 & $100,00 \%$ \\
\hline
\end{tabular}


Table II Constructs, calibration and membership scores

\begin{tabular}{lll}
\hline Construct & Calibration rule & Membership score \\
\hline High innovation performance (inn) & If inn $<0.60$ & 0 (full non-membership) \\
& If inn $=0.95$ & 0.5 (cross-over point) \\
& Ifinn $>1.65$ & 1 (full membership) \\
High partner technological relatedness (tec) & Iftec $<732.0$ & 0 (full non-membership) \\
& Iftec $=1283.0$ & 0.5 (cross-over point) \\
Horizontal partner competitive overlap (com) & Iftec $>2832.5$ & 1 (full membership) \\
& Ifcom $<0.1$ & 0 (full non-membership) \\
& Ifcom $=0.5$ & 0.5 (cross-over point) \\
Partner specificexperience (exp) & Ifcom $>0.9$ & 1 (full membership) \\
& Ifexp $<2.50$ & 0 (full non-membership) \\
& Ifexp $=11.0$ & 0.5 (cross-over point) \\
Large partner relative size (siz) & Ifexp $>23.25$ & 1 (full membership) \\
& Ifsiz $<27.778$ & 0 (full non-membership) \\
& Ifsiz $=95.1724$ & 0.5 (cross-over point) \\
& Ifsiz $>204.0$ & 1 (full membership) \\
\hline
\end{tabular}

Table III Truth table without the remainders

\begin{tabular}{cccccc}
\hline $\begin{array}{l}\text { High innovation } \\
\text { performance } \\
\text { (inn) }\end{array}$ & $\begin{array}{l}\text { High partner } \\
\text { technological } \\
\text { relatedness (tec) }\end{array}$ & $\begin{array}{l}\text { Horizontal } \\
\text { partner } \\
\text { competitive } \\
\text { overlap (com) }\end{array}$ & $\begin{array}{l}\text { Partner } \\
\text { specificexperience } \\
\text { (exp) }\end{array}$ & $\begin{array}{l}\text { Large partner } \\
\text { relative size } \\
\text { (siz) }\end{array}$ & $\begin{array}{l}\text { N. of cases per } \\
\text { configuration }\end{array}$ \\
\hline 1 & 1 & 1 & 0 & 0 & $2^{*}$ \\
1 & 0 & 1 & 1 & 0 & $1^{*}$ \\
0 & 1 & 1 & 1 & 0 & 1 \\
0 & 1 & 0 & 1 & 0 & 1 \\
0 & 1 & 0 & 0 & 0 & 1 \\
0 & 0 & 1 & 0 & 0 & 9 \\
0 & 0 & 0 & 1 & 0 & 3 \\
C & 0 & 0 & 0 & 1 & 2 \\
C & 0 & 0 & 0 & 0 & 7 \\
\hline
\end{tabular}

C: contradictory row (Schneider and Wagemann, 2012).

Table IV Sufficient configurations for high innovation performance, consistency, and coverage

High innovation performance $\mathrm{f}\{$ High partner technological relatedness (tec),

Horizontal partner competitive overlap (com), Partner specific experience (exp),

Large partner relative size (siz)

Raw

Solution path $1:$ tec $*$ com $* \sim \exp$

Consistency Coverage

Solution path2: $\sim \operatorname{tec} * \operatorname{com} * \exp$

0.946

0.194

$\sim:$ absence of a condition (Schneider andWagemann, 2012).

*: logical AND (conjunction, intersection). 